\title{
Adolescent SBIRT implementation in pediatric primary care: results from a randomized trial in an integrated health-care delivery system
}

\author{
Stacy Sterling ${ }^{1 *}$, Andrea Kline-Simon ${ }^{1}$, Constance Weisner ${ }^{1,2}$, Ashley Jones $^{1}$, Derek Satre ${ }^{1,2}$, Anna Wong ${ }^{3}$ \\ From 2014 Addiction Health Services Research (AHSR) Conference \\ Boston, MA, USA. 15-17 October 2014
}

\section{Background}

Substance misuse by adolescents is associated with significant mortality and morbidity [1-9]. In spite of growing evidence on the effectiveness of Screening, Brief Intervention and Referral to Treatment (SBIRT) for adolescents [10-25], it has not been widely implemented in pediatric health-care settings. We describe implementation findings from a trial of different modalities of SBIRT for adolescents during primary care well-visits.

\section{Materials and methods}

We randomized pediatricians $(\mathrm{N}=52)$ from a general pediatrics clinic in an integrated health-care delivery system to three study arms: a "PCP" arm, where pediatricians were trained to deliver SBIRT; a "BHC" arm, where providers referred adolescents who endorsed alcohol or drug (AOD) use or mood symptoms to a behavioral health clinician for SBIRT; and a usual care (UC) arm, where providers had access to assessment tools in the electronic health record (EHR), and referral resources, but were not trained in SBIRT. We used EHR data to examine screening, problem identification, brief intervention, and referral to treatment rates. Brief interventions could focus on alcohol and other drug (AOD) use, mental health $(\mathrm{MH})$, or both problems.

\section{Results}

During the study period there were 8981 well visits; 73 percent of these received initial screening. Initial screening rates were significantly higher in both intervention arms, compared to the UC arm $(\mathrm{p}<.05)$. A higher percentage of patients endorsed mood symptoms in the PCP arm

\footnotetext{
* Correspondence: Stacy.A.Sterling@kp.org

${ }^{1}$ Kaiser Permanente Division of Research, Oakland, California, 94612, USA

Full list of author information is available at the end of the article
}

$(16.4 \%, \mathrm{BHC}=12.6 \%, \mathrm{UC}=13.7 \% ; \mathrm{p}<.001)$; endorsement of AOD symptoms did not significantly differ across arms. Approximately 30 percent of teens in each arm were candidates for further assessment, having endorsed at least one of the five AOD or mood risk behavior questions (ns). The percentage of patients endorsing any mood symptoms, who were further assessed per the established SBIRT protocol, was significantly higher in the BHC arm compared to the PCP arm ( $\mathrm{p}<.001)$; further assessment per the protocol among those with any AOD symptoms was significantly higher in the PCP arm $(\mathrm{p}<.001)$. Among those eligible, 25.8 percent in the $\mathrm{BHC}$ arm, 16.5 percent in the PCP arm, and 1.8 percent in the $\mathrm{UC}$ arm received a BI $(\mathrm{p}<.001)$. The percentage of BIs containing any AOD content was significantly higher in the PCP arm compared to the $\mathrm{BHC}$ arm $(92.6 \%$ vs. $59.1 \%)$, and the $\mathrm{BHC}$ arm delivered more BIs with any $\mathrm{MH}$ content $(81.8 \%$ vs. $10.3 \%)$, both $\mathrm{p}<.001$.

\section{Conclusions}

The two intervention arms demonstrated better implementation of different SBIRT components. Findings illustrate challenges to addressing adolescent behavioral health needs inherent in the different models.

\footnotetext{
Authors' details

${ }^{1}$ Kaiser Permanente Division of Research, Oakland, California, 94612, USA.

${ }^{2}$ University of California San Francisco, San Francisco, California, 94143, USA. ${ }^{3}$ The Permanente Medical Group, Kaiser Permanente Division of Research, Oakland, CA, 94612, USA.
}

Published: 20 February 2015

References

1. Subramaniam GA, Volkov ND: Substance misuse among adolescents: To screen or not to screen? JAMA Pediatr 2014. 
2. Ammon L, Sterling S, Mertens J, Weisner C: Adolescents in private chemical dependency programs: Who are most at risk for HIV? J Subst Abuse Treat 2005, 29(1):39-45.

3. Sterling S, Weisner C: Chemical dependency and psychiatric services for adolescents in private managed care: Implications for outcomes. Alcohol Clin Exp Res 2005, 29(5):801-809.

4. Mertens JR, Flisher AJ, Fleming MF, Weisner CM: Medical conditions of adolescents in alcohol and drug treatment: Comparison with matched controls. J Adolesc Health 2007, 40(2):173-179.

5. Jacobus J, Tapert SF: Neurotoxic effects of alcohol in adolescence. Annu Rev Clin Psychol 2013, 9:703-721.

6. Brown SA, Tapert SF, Granholm E, Delis DC: Neurocognitive functioning of adolescents: Effects of protracted alcohol use. Alcohol Clin Exp Res 2000 24(2):164-171.

7. Volkow ND, Baler RD: Foreword. Substance use and abuse among adolescents. Adolesc Med State Art Rev 2014, 25(1):xv-xvi.

8. Schweinsburg AD, Brown SA, Tapert SF: The influence of marijuana use on neurocognitive functioning in adolescents. Curr Drug Abuse Rev 2008, 1(1):99-111.

9. O'Shea M, Singh ME, McGregor IS, Mallet PE: Chronic cannabinoid exposure produces lasting memory impairment and increased anxiety in adolescent but not adult rats. J Psychopharmacol 2004, 18(4):502-508.

10. Monti PM, Colby SM, Barnett NP, et al: Brief intervention for harm reduction with alcohol-positive older adolescents in a hospital emergency department. J Consulting Clin Psychol 1999, 67(6):989-994.

11. Maio RF, Shope JT, Blow FC, et al: A randomized controlled trial of an emergency department-based interactive computer program to prevent alcohol misuse among injured adolescents. Ann Emerg Med 2005, 45(4):420-429.

12. Neighbors CJ, Barnett NP, Rohsenow DJ, Colby SM, Monti PM: Costeffectiveness of a motivational intervention for alcohol-involved youth in a hospital emergency department. J Stud Alcohol Drugs 2010, 71(3):384-394.

13. Tait RJ, Hulse GK, Robertson SI: Effectiveness of a brief-intervention and continuity of care in enhancing attendance for treatment by adolescent substance users. Drug Alcohol Depend 2004, 74(3):289-296.

14. Tait RJ, Hulse GK, Robertson SI, Sprivulis PC: Emergency department-based intervention with adolescent substance users: 12-month outcomes. Drug Alcohol Depend 2005, 79(3):359-363.

15. Cunningham RM, Chermack ST, Zimmerman MA, et al: Brief motivational interviewing intervention for peer violence and alcohol use in teens: One-year follow-up. Pediatrics 2012, 129(6):1083-1090.

16. Cunningham RM, Walton MA, Goldstein A, et al: Three-month follow-up of brief computerized and therapist interventions for alcohol and violence among teens. Acad Emer Med 2009, 16(11):1193-1207.

17. Walton MA, Bohnert $K$, Resko $S$, et al: Computer and therapist based brief interventions among cannabis-using adolescents presenting to primary care: One year outcomes. Drug Alcohol Depend 2013, 132(3):646-653.

18. Walton MA, Chermack ST, Shope JT, et al: Effects of a brief intervention for reducing violence and alcohol misuse among adolescents: A randomized controlled trial. JAMA 2010, 304(5):527-535.

19. Bernstein E, Edwards E, Dorfman D, Heeren T, Bliss C, Bernstein J: Screening and brief intervention to reduce marijuana use among youth and young adults in a pediatric emergency department. Acad Emerg Med 2009, 16(11):1174-1185.

20. Bernstein J, Heeren $T$, Edward $E$, et al: A brief motivational interview in a pediatric emergency department, plus 10-day telephone follow-up, increases attempts to quit drinking among youth and young adults who screen positive for problematic drinking. Acad Emerg Med 2010, 17(8):890-902

21. Spirito A, Monti PM, Barnett NP, et al: A randomized clinical trial of a brief motivational intervention for alcohol-positive adolescents treated in an emergency department. J Pediatr 2004, 145(3):396-402.

22. Spirito A, Sindelar-Manning H, Colby SM, et al: Individual and family motivational interventions for alcohol-positive adolescents treated in an emergency department: results of a randomized clinical trial. Arch Pediatrics Adolescent Med 2011, 165(3):269-274

23. De Micheli D, Fisberg M, Formigoni ML.: Study on the effectiveness of brief intervention for alcohol and other drug use directed to adolescents in a primary health care unit. Rev Assoc Med Bras 2004, 50(3):305-313.
24. Harris SK, Csemy L, Sherritt L, et al: Computer-facilitated substance use screening and brief advice for teens in primary care: An international trial. Pediatrics 2012, 129(6):1072-1082

25. Tanner-Smith EE, Lipsey MW: Brief alcohol interventions for adolescents and young adults: A systematic review and meta-analysis. J Subst Abuse Treat 2014.

doi:10.1186/1940-0640-10-S1-A62

Cite this article as: Sterling et al: Adolescent SBIRT implementation in pediatric primary care: results from a randomized trial in an integrated health-care delivery system. Addiction Science \& Clinical Practice 2015 10(Suppl 1):A62.

\section{Submit your next manuscript to BioMed Central and take full advantage of:}

- Convenient online submission

- Thorough peer review

- No space constraints or color figure charges

- Immediate publication on acceptance

- Inclusion in PubMed, CAS, Scopus and Google Scholar

- Research which is freely available for redistribution 